\title{
Executive functions in major depressive disorder
}

\author{
K Dhawan, CY Sudarshan, S Begum
}

\section{Abstract \\ Background}

It is reported that executive functions are impaired in a variety of neuropsychiatric syndromes, including depressive disorders. Studies on executive functions in depressive disorders are inconclusive.

\section{Methods}

A total of 50 drug naïve patients with major depressive disorder were included in the study. The severity of depression was measured using the Hamilton Depression Rating Scale (HAM-D), and executive functions were assessed using the Digit Symbol Substitution Test, Digit Vigilance Test, Controlled Oral Word Association Test, Animal naming test, Verbal $\mathrm{N}$ back (1\&2) test, Trail making test A \& B and Stroop test as per the NIM HANS Neuropsychology Battery 2004 manual.

Results

The mean age of the sample was 31.9 years. Females constituted $60 \%$ of the sample. A majority were Hindus, nearly $75 \%$ were from semi-urban areas, $66 \%$ were married, and $58 \%$ had a college education.

Depression was associated with poor performance on executive functions except for working memory and set shifting. Older age, greater severity of depression, a longer duration of illness and the duration of the present episode were associated with poor performance on executive functions. A higher level of education was associated with better performance on executive functions.

\section{Conclusions}

This cross-sectional assessment suggests that some aspects of executive functions are impaired in patients with major depressive disorder. Further studies in remitted patients, controlled for age, and education level are suggested.

Key words: Major depressive disorder, executive functions, melancholic depression, cognitive functions

SLJ Psychiatry 2018; 9(1): 20-25

\section{Introduction}

Major depressive disorder (MDD) is a common condition with a high rate of recurrence, chronicity, and a significant economic burden, including disability in the work force. In addition to work impairment, the psychosocial impact of MDD often affects a person's level of functioning in the family and social relationships.

While there is clearly an association between improvement in depressive symptoms and functioning with treatment, symptom improvement can be dissociated from functional improvement and work loss. Cognitive dysfunction may be a primary mediator of functional impairment in MDD(1).

Executive functions (EF) are a set of cognitive processes which include the ability to formulate goals, plan and perform effectively $(2,3,4)$. It allows a person to respond flexibly to the environment; to break out of habits, make decisions and evaluate risks, plan for the future, prioritise and sequence actions and cope with novel situations. It makes an individual independent, creative and socially integrated (5). These functions are disturbed in deficits of functioning in frontal lobe, parietal lobe, cingulate cortex, basal ganglia and cerebellar lesions. Functional neuroimaging studies in depression have also documented dysregulation in neural circuits involving the frontal cortex, thalamus, limbic system and basal ganglia.

Depressive disorders may also be associated with frontal dysfunctions. Hence depressive disorders may be associated with deficits in several neuro-cognitive functions including executive functioning abilities $(6,7)$.

Examination of cognitive functions in major psychiatric illness has mostly focused on mental operations underlying goal directed behaviour such as attention, working memory, processing speed, learning and memory, executive functions and global intellectual functions including intelligence quotient (IQ). 
Several studies have consistently reported impairment of executive functioning in depression across various age groups $(7,8)$. The severity of depression has been reported to be associated with impaired executive functioning (7). Further studies have examined the relationship between neurocognitive dysfunction and factors such as age, age of onset, duration of illness and number of episodes and results have been equivocal (911). Endogenous (melancholic) depression has been reported to be associated with greater impairment of executive functioning compared to non-endogenous depression $(9,12,13)$.

Despite the importance of this subject, there is a lack of published research in this area in South Asia. The objective of this study was to examine for cognitive markers in patients with major depressive disorder.

\section{Methods}

This was a hospital based cross-sectional study conducted at Bapuji Hospital, which is attached to JJM Medical College, Davangere, India.

The study received ethical approval from the institutional ethics review committee, and only those who gave written informed consent were included in the study.

The sample consisted of 50 patients diagnosed to have MDD as per DSM V criteria. They were drug naïve, aged between 18-45 years, and belonged to both genders. Only those who had a formal scholastic education upto at least the 7th standard were included. Patients with other psychiatric diagnoses, coexisting neurological disorders that impaired executive functions, severe medical illnesses interfering with the assessment of depression and executive functions, and those with substance use disorders were excluded from the study.

After recording details of socio demographic data, the severity of depression was assessed using the Hamilton Depression Rating Scale. Executive functions were assessed as per the protocol suggested by NIMHANS Neuropsychological Battery 2004, as follows:

Psychomotor speed was assessed using the Digit Symbol Substitution Test (DSST). Attention was assessed using Digit Vigilance test (DVT) and Trail making test A and B (TMT A, TMT B). Phonemic fluency was assessed using Controlled Oral Word Association Test (COWAT). Categorical fluency was evaluated using Animal naming test. Working memory was assessed using Verbal N back test. Response inhibition was evaluated using Stroop test.
Analysis was done using IBM SPSS version 22 for Windows. Categorical variables were expressed as frequencies and percentages, and continuous variables as mean and standard deviation (SD). The mean differences between the groups were assessed with the unpaired t test. The Pearsons correlation coefficient was used to assess variation between cognitive functions and clinical variables.

\section{Results}

The mean age of the sample was 31.9 years. Females constituted $60 \%$ of the sample. A majority of patients were Hindus, nearly $75 \%$ were from semi-urban areas, $66 \%$ were married, and $58 \%$ of the sample had a college education (Table I).

Older subjects performed poorly on the DSST, DVT, TMT A and B, COWAT and Animal naming test. A higher level of education was significantly associated with a better performance on all tests except the Stroop test, but this difference was not significant.

The mean duration of illness in the sample was 58 months (SD \pm 72.7 ), the mean duration of the present episode was 3.4 months ( $\mathrm{SD} \pm 4.1$ ), and $75 \%$ of the sample had experienced one to two episodes. The mean HAM-D score of the sample was 14.9 (SD \pm 3.8 ), and $80 \%$ of the sample had mild to moderate depression (Table 2, 3).

The performance of patients on various executive function tests is shown in Table 4. Performance on the Verbal N back (1) test and TMT B was on par with normative data. Performances on the Verbal N back (2) test, TMT A, COWAT and Animal naming test were deficient in $4-10 \%$ of patients. With regards to the DSST and DVT, $32 \%$ and $30 \%$ of patients showed deficits respectively. All the subjects performed poorly in the Stroop test except for $4 \%$ of the sample.

The severity of depression was associated with poor performance in all executive functions, but was significantly poor for the Verbal N Back (1 and 2) tests (Table 5).

The duration of illness was positively correlated with poorer performance on the Verbal 1 back test and Stroop test, which was statistically significant. The duration of the present episode was positively correlated with a poorer performance on Verbal 2 back test (Table 6). The DSST and TMT B were negatively correlated with performance on executive functions, but this was not statistically significant. 
Table 1. Socio demographic details

\begin{tabular}{|c|c|c|c|}
\hline Factors & & Frequency & Percent \\
\hline \multicolumn{2}{|l|}{ Age in years (M ean $\&$ SD) } & \multicolumn{2}{|c|}{$31.86 \pm 6.68$} \\
\hline \multirow{2}{*}{ Sex } & Male & 20 & 40.0 \\
\hline & Female & 30 & 60.0 \\
\hline \multirow{3}{*}{ Place } & Rural & 7 & 14.0 \\
\hline & Semi-Urban & 36 & 72.0 \\
\hline & Urban & 7 & 14.0 \\
\hline \multirow{2}{*}{ Religion } & Hindu & 43 & 86.0 \\
\hline & Muslim & 7 & 14.0 \\
\hline \multirow{2}{*}{ Education } & School & 21 & 42 \\
\hline & College & 39 & 58 \\
\hline \multirow{6}{*}{ Occupation } & Student & 5 & 10.0 \\
\hline & House wife & 23 & 46.0 \\
\hline & Unskilled & 3 & 6.0 \\
\hline & Agriculture & 8 & 16.0 \\
\hline & Business & 3 & 6.0 \\
\hline & Salaried job & 8 & 16.0 \\
\hline \multirow{2}{*}{ Marital Status } & Married & 32 & 64.0 \\
\hline & unmarried & 18 & 36.0 \\
\hline \multirow{2}{*}{ Type of Family } & Nuclear & 22 & 44.0 \\
\hline & Extended & 28 & 56.0 \\
\hline \multirow{3}{*}{ Socio economic status } & Lower & 21 & 42.0 \\
\hline & Middle & 26 & 52.0 \\
\hline & Upper & 3 & 6.0 \\
\hline
\end{tabular}

\begin{tabular}{|l|c|c|c|c|c|}
\hline \multicolumn{1}{|c|}{ Table 2. Clinical variables } \\
\hline Variable & Mean & SD & M inimum & Maximum & Range \\
\hline Duration of illness (months) & 58.0 & 72.7 & 2.0 & 268.0 & 266.0 \\
\hline $\begin{array}{l}\text { Duration of present } \\
\text { episode (months) }\end{array}$ & 3.4 & 4.1 & 0.3 & 18.0 & 17.7 \\
\hline HAM -D & 14.9 & 3.8 & 10.0 & 23.0 & 13.0 \\
\hline
\end{tabular}

\begin{tabular}{|c|l|c|c|}
\hline \multicolumn{2}{|c|}{ Table 3. Clinical variables } \\
\hline \multirow{3}{*}{ Variable } & & Frequency & Percentage \\
\hline \multirow{3}{*}{ Total number of episodes } & One & 16 & 32.0 \\
& Two & 21 & 42.0 \\
& Three & 11 & 22.0 \\
& Four & 2 & 4.0 \\
\hline \multirow{3}{*}{ HAM -D Categories } & Mild & 25 & 50.0 \\
& Moderate & 15 & 30.0 \\
& Severe & 7 & 14.0 \\
& Very severe & 3 & 6.0 \\
\hline
\end{tabular}


Executive functions in Major Depressive Disorder

\begin{tabular}{|l|r|r|r|r|r|}
\hline \multicolumn{7}{|c|}{ Table 4. Executive functions } \\
\hline Test & Mean & \multicolumn{1}{|c|}{ SD } & M inimum & Maximum & Range \\
\hline Digit symbol substitution test & 277.0 & 122.9 & 147.0 & 663.0 & 516.0 \\
Digit Vigilance test & 560.8 & 188.1 & 323.0 & 1133.0 & 810.0 \\
1 Back test & 8.8 & 0.4 & 8.0 & 9.0 & 1.0 \\
2 Back Test & 7.8 & 0.9 & 5.0 & 9.0 & 4.0 \\
TMT-A & 53.2 & 23.5 & 22.0 & 110.0 & 88.0 \\
TM T-B & 103.8 & 39.9 & 38.0 & 180.0 & 142.0 \\
COWAT (Average score) & 9.7 & 2.8 & 4.3 & 15.6 & 11.3 \\
Animal naming & 13.6 & 2.4 & 9.0 & 18.0 & 9.0 \\
Stroop test & 347.8 & 85.7 & 238.0 & 528.0 & 290.0 \\
\hline
\end{tabular}

\section{Table 5. Severity of depression and performance on executive function tests}

\begin{tabular}{|l|r|c|c|c|c|c|}
\hline \multirow{2}{*}{ Test } & \multicolumn{2}{|c|}{$\begin{array}{c}\text { Mild-M od } \\
(\mathrm{N}=40)\end{array}$} & \multicolumn{2}{c|}{$\begin{array}{c}\text { Severe \& V. } \\
\text { Severe }(\mathrm{N}=10)\end{array}$} & \multicolumn{2}{c|}{ Unpaired t test } \\
\hline & Mean & $\begin{array}{c}\text { Std. } \\
\text { Deviation }\end{array}$ & Mean & $\begin{array}{c}\text { Std. } \\
\text { Deviation }\end{array}$ & t Value & $\mathrm{p}$ Value \\
\cline { 2 - 7 } Digit symbol substitution test & 270.6 & 122.0 & 302.4 & 129.8 & -0.728 & $\mathrm{p} \varangle 0.470$ \\
Digit Vigilance test & 573.3 & 198.4 & 510.9 & 136.0 & 0.938 & $\mathrm{p} \varangle 0.353$ \\
1 Back test & 8.8 & 0.4 & 8.5 & 0.5 & 2.29 & $\mathrm{p} \varangle 0.03$ \\
2 Back Test & 7.9 & 1.0 & 7.2 & 0.4 & 2.29 & $\mathrm{p} \varangle 0.02$ \\
TMT-A & 51.0 & 20.6 & 62.1 & 32.6 & -1.34 & $\mathrm{p} \varangle 0.186$ \\
TM T-B & 103.2 & 40.6 & 106.5 & 38.6 & -0.235 & $\mathrm{p} \varangle 0.815$ \\
COWAT (Average score) & 9.8 & 2.6 & 9.6 & 3.8 & 0.212 & $\mathrm{p} \varangle 0.833$ \\
Animal naming test & 13.7 & 1.9 & 13.0 & 3.9 & 0.831 & $\mathrm{p} \varangle \varangle .410$ \\
Stroop test & 349.7 & 93.1 & 340.2 & 48.1 & 0.311 & $\mathrm{p} \varangle 0.757$ \\
\hline
\end{tabular}

\section{Table 6. Correlation between duration of illness and executive functions}

\begin{tabular}{|l|l|l|}
\hline Executive functions tests & Duration of illness & $\begin{array}{c}\text { Duration of } \\
\text { present episode }\end{array}$ \\
\hline Digit symbol substitution test & $-0.055, \mathrm{NS}$ & $-0.250, \mathrm{NS}$ \\
Digit vigilance test & $0.209, \mathrm{NS}$ & $0.001, \mathrm{NS}$ \\
1 Back test & $0.398, \mathrm{p} \varangle 0.004$ & 50.256 \\
2 Back Test & $0.122, \mathrm{NS}$ & $0.344, \mathrm{p} \varangle 0.01$ \\
TMT-A & $0.008, \mathrm{NS}$ & $-0.091, \mathrm{NS}$ \\
TM T-B & $-0.096, \mathrm{NS}$ & $-0.142, \mathrm{NS}$ \\
COWAT (Average score) & $0.064, \mathrm{NS}$ & $0.004, \mathrm{NS}$ \\
Animal naming test & $0.076, \mathrm{NS}$ & $0.126, \mathrm{NS}$ \\
Stroop test & $0.526, \mathrm{p} \varangle 0.001$ & $-0.087, \mathrm{NS}$ \\
\hline
\end{tabular}




\section{Discussion}

All the participants had a poor performance on executive functions on all the tests administered, except for the Verbal 1 back and TMT B, suggesting deficits in psychomotor speed, attention, phonemic fluency, categorical fluency and response inhibition. Good performance on the Verbal N back (1) and TMT B suggested adequate functions in working memory and set shifting domains. Deficits in several neurocognitive domains such as psychomotor speed, verbal and visual explicit memory and set shifting were consistently impaired across all age groups $(6,7)$.

In the present study, the sample consisted of patients who had a formal education upto the 7th standard or above. A higher level of education was significantly associated with a better performance on all tests except the Stroop test, in which the difference was not significant.

A longer duration of illness and a longer duration of the present episode were associated with poorer performance on the Verbal 1 back, Stroop test and Verbal 2 back test respectively. Previous research evaluating these variables have yielded inconclusive results (10).

Poor performance on the DSST and DVT i.e., 30\% and $32 \%$ respectively, and poorer performance on the Stroop test in the present sample is in line with existing literature $(14,15,16,17)$. But some other studies have reported no difference in performance of executive functions between depressed and control groups $(18,19)$.

The performance on the Verbal 1 back and TMT B in this study sample was on par with normative data. However, one Indian study has reported contradictory findings, with poorer performance being noted with the TMT B test (20).

The severity of depression in our study was associated with poorer performance on all executive functions, and it was significantly poor in the Verbal N Back (1 and 2) tests. This finding is in accordance with previous studies $(7,9,21)$. In contrast, a previous study by Hammar et al., showed poor performance on executive functions in depressed patients in general, but there was no association between the severity of depression and executive functions (8). Thus, the understanding and knowledge regarding the relationship between depression severity and neuro cognitive sequelae appears to be limited and somewhat conflicting (10).

Performances in the DSST and TMT B were negatively correlated with the severity of depression, but this finding was not statistically significant. The fact that patients with higher levels of education who had severe depression may have performed better on the tests compared to others with same severity of depression, may have influenced this finding.

Executive function is not a single entity and has several subcomponents. The syndrome of depression also varies with respect to severity and subtypes. It is also difficult to distinguish MDD from bipolar disorder. These factors may explain the differences in the results across studies, and may also limit the generalization of findings. Medication received by the patients may be another confounding factor. However this study was done on drug naïve patients.

\section{Limitations}

Limitations of this study include the fact that it was a cross sectional study, and further, there was no control group - comparisons were done with normative data only. Further, despite being educated upto or above the 7th standard many patients had difficulty in comprehending and performing some of the tests, which could be due to cultural factors and the nature of the assessment tools.

\section{Conclusions}

The findings of this study suggest that depression is associated with poor performance on executive functions, except for working memory and set shifting. A higher level of education was associated with better executive functions. Older age, a greater severity of depression, longer duration of illness and duration of present episode were associated with poorer performances on tests of executive functions. The deficits of executive functions elicited among depressed patients in this study points towards abnormalities of functioning mainly in the anterior cingulate cortex, orbito frontal cortex, subcortical ganglia and locus coeruleus.

Future research should focus on longitudinal assessment of patients after remission of depression, and comparison of differences in age, gender and education, using matched control groups.

\section{Declaration of interest}

None

K Dhawan, CY Sudarshan, S Begum, Department of Psychiatry, JJM M edical College, India

Corresponding author: Karan Dhawan

Email: karan91dhawan@gmail.com

http://orcid.org/0000-0002-8981-5200 


\section{References}

1. Lam RW, Filteau MJ, Milev R. Clinical effectiveness: the importance of psychosocial functioning outcomes. J Affect Disord. 2011; 132(Suppl 1): S9-S1.

2. Stern RA, Prohaska ML. Neuropsychological Evaluation of Executive Functioning. Am Psychiatric Press Rev Psychiatry 1996; 15: 243-66.

3. Lezak MD. Relationship between personality disorders, social disturbances and physical disability following traumatic brain injury. J Head Trauma Rehabil 1987; 2: 57-69.

4. Lezak MD. The problem of assessing executive functions. Intl J Psychol 1982; 17: 281-97.

5. Ustárroz JT, Céspedes JMM, Valero CP. Funciones ejecutivas necesidad de una integración conceptual. Rev Neurol 2002; 34(7): 673-85.

6. Baune BT, Czira ME, Smith AL et al. Neuropsychological performance in a sample of 13-25 year olds with a history of nonpsychotic major depressive disorder. J Affect Disord 2012; 141: 441-8.

7. Snyder HR. Major depressive disorder is associated with broad impairments on neuropsychological measures of executive function: a meta-analysis and review. Psychol Bull 2013; 139: 81-132.

8. Hammar A, Strand M, Ardal G, et al. Testing the cognitive effort hypothesis of cognitive impairment in major depression. Nord J Psychiatry 2011; 65: 74-80

9. McDermott LM, Ebmeier KP. A meta-analysis of depression severity and cognitive function. J Affect Disord 2009; 119: 1-8.

10. McClintock SM, Husain MM, Greer TL et al. Association between depression severity and neurocognitive function in major depressive disorder: a review and synthesis. Neuropsychology 2010; 24: 9-34.

11. Fossati P, Harvey PO, Le Bastard G et al. Verbal memory performance of patients with a first depressive episode and patients with unipolar and bipolar recurrent depression. J Psychiatr Res 2004; 38: 137-44.

12. Quinn C, Harris A, Kemp A. The Interdependence of Subtype and Severity, Contributions of Clinical and Neuropsychological Features to Melancholia and Nonmelancholia in an Outpatient Sample. J Int Neuropsychol Society 2012; 18: 361-9.

13. Naismith SL, Hickie IB, Turner K et al. Neuropsychological performance in patients with depression is associated with clinical,etiological and genetic risk factors. J Clin Exp Neurosci 2003; 25: 866-77.

14. Gohier B, Ferracci L, Surguladze SA, et al. Cognitive inhibition and working memory in unipolar depression $\mathrm{J}$ Affect Disord 2009; 116: 100-5.

15. Hammar A, Sorenser L, Ardal G, et al. Enduring cognitive dysfunction in unipolar major depression, A test-retest study using the Stroop paradigm. Scand J Psychol 2010; 51: 304-8.

16. Hasselbalch BJ, Knorr U, Hasselbalch SG, et al. Cognitive Deficits in the Remitted State of Unipolar Depressive Disorder. Neuropsychology 2012; 26(5): 642-51.

17. Reppermund S, Ising M, Lucae S, Zihl J. Cognitive impairment in unipolar depression is persistent and nonspecific, further evidence for the final common pathway disorder hypothesis. Psychol Med 2009; 39: 603-14.

18. Yamamoto T, Shimada H. Cognitive Dysfunctions after Recovery from Major Depressive Episodes. Appl Neuropsychol Adult 2012; 19(3): 183-91.

19. Preiss M, Kucerova H, Lukavsky J, et al. Cognitive deficits in the euthymic phase of unipolar depression. Psychiatry Res 2009; 169: 235-9.

20. Mondal S, Sharma VK, Das S, et al. Neuro-cognitive functions in patients of Major Depression. Ind J Physiol Pharmacol 2007; 51(1): 69-75.

21. Paelecke-Habermann Y, Pohl J, Leplow B. Attention and executive functions in remitted major depression patients. J Affect Disord 2005; 89: 125-35. 